\title{
Development of a Bioactive Scaffold based on NGF Containing PCL/Chitosan Nanofibers for Nerve Regeneration
}

\author{
Hamed Afrash ${ }^{1}$, Niloofar Nazeri ${ }^{1}$, Parivash Davoudi ${ }^{1}$, Reza Faridi_Majidi ${ }^{1}$ (D) , Hossein Ghanbari 1 ${ }^{\text {** }}$ (D) \\ 1 Regenerative Nanomedicine Research Group, Department of Medical Nanotechnology, School of Advanced Technologies \\ in Medicine, Tehran University of Medical Sciences, Tehran, Iran \\ * Correspondence: hghanbari@tums.ac.ir;
}

Scopus Author ID 37031133600

Received: 20.12.2020; Revised: 15.01.2021; Accepted: 18.01.2021; Published: 30.01.2021

\begin{abstract}
Nanofibers are used in a wide range of applications, including scaffolds for tissue engineering. Electrospinning is a promising technique to fabricate nanofibrous scaffolds capable of supporting cell attachment and growth. Nanofibers with biomimetic alignment could also guide neural cell growth and orientation of cell processes necessary for peripheral nerve regeneration. This study fabricated aligned nanofibers of polycaprolactone/chitosan (PCL/CS) scaffolds and immobilized nerve growth factor (NGF) on them via dopamine coating mediated bonds to confer bioactivity to the scaffold and support attachment and growth of PC12 cells. The results showed that PCL/CS nanofibrous scaffolds revealed appropriate mechanical and surface properties. Cells remained viable on the scaffolds, and surface-modified aligned nanofibrous scaffolds interacted better with the cells, inducing neural morphology and orientation. Immobilization of NGF via polydopamine (PD) on nanofibers' surface proved to be a proper method to enhance PC12 cell attachment and proliferation. Thus, this construct could potentially be used as a scaffold for peripheral nerve regeneration.
\end{abstract}

Keywords: nanofiber; scaffold; chitosan; polycaprolactone; nerve growth factor; tissue engineering.

(C) 2021 by the authors. This article is an open-access article distributed under the terms and conditions of the Creative Commons Attribution (CC BY) license (https://creativecommons.org/licenses/by/4.0/).

\section{Introduction}

Peripheral nerve injuries occur in 200000 cases every year around the globe. Strategies such as applying autografts, allografts, and xenografts are fairly limited due to loss of function at the donor site, potential immune reactions, limited availability of donors and need for multiple surgeries $[1,2]$. Due to these reasons, scaffolds fabricated from natural and synthetic polymers have been studied for nerve tissue regeneration. An ideal scaffold should mimic the nanofibrous structure of native ECM to help the damaged tissue repair by neighboring cells $[3,4]$. Electrospinning has been commonly used to fabricate the nanofibers scaffolds[5]. These scaffolds mimic the collagen fibrils and increased surface area to support cell attachment[6]. Synthetic polymers such as PCL, PLA, and PLGA have been investigated as scaffolds for nerve regeneration [7]. Although they are biocompatible and biodegradable, synthetic polymers cannot support cell adhesion because they are typically hydrophobic and lack cell recognizing sites [8]. On the other hand, natural polymers like chitosan (CS) and collagen are hydrophilic and biocompatible [9-11]. To take the advantages of both PCL and CS for nerve regeneration, polymer blending has been used. PCL/CS blends are miscible and do not require a toxic crosslinking agent [12]. In nerve regeneration, aligned fibers have shown increased cell 
attachment and nerve cell growth [12]. Since neurotrophic activity is critical for nerve regeneration, scaffolds with these properties better support cell survival and differentiation of neural and modulates injured nerve repair [13,14]. Results of recent studies showed that immobilized NGF has a positive effect on sprouting and neurite outgrowth in different cells such as PC12 cells, hippocampal neurons, and dorsal root ganglion (DRG) neurons $[15,16]$. The diffusion of NGF administered in solution from injury sites needs periodic injection, and it is impractical. Immobilization of NGF on the scaffold can solve this problem [17,18]. Most studies that immobilize NGF on to the scaffolds have used complicated methods for chemical activations [19]. However, these methods can change scaffolds properties and induce surface denaturation. Besides, chemicals such as NHS (N-hydroxysuccinimide) used for immobilization may be hydrolyzed during the reaction which can decrease surface conjugation efficacy [20].

To overcome these limitations, natural adhesives have attracted broad interest. The strong adhesion of mussels to any surface results from an extensive repeat of 3, 4-dihydroxyL-phenylalanine (dopamine) and lysine residues in the mussel adhesive pads [7,21-23].

In this study, we fabricated PCL/CS nanofibers and fully characterized their properties. To have active scaffolds for nerve regeneration NGF as a neurotrophin was immobilized on the PCL/CS nanofibers via dopamine coating. Dopamine was used to conjugate NGF onto the scaffold and improve the cell-adhesive characteristic of scaffolds [21]. Finally, we evaluated the effects of dopamine and NGF on the adhesion and proliferation of cells.

\section{Materials and Methods}

\subsection{Materials.}

Diacetate (4,6-diamidino-2-phenylindole) (DAPI), Tris (trisaminomethane), polycaprolactone, and chitosan with a molecular weight of 80 and $100 \mathrm{kDa}$, respectively were purchased from Sigma Aldrich. 3-Hydroxytyraminim chloride and all solvents such as trifluoroacetic acid (TFA), 2,2,2-trifluoroethanol, and methanol were obtained from Merck. PC12 cells were purchased from ATCC (CRL-1721). Fetal bovine serum and RPMI were purchased from Gibgo. Nerve growth factor from Vipera lebetina venom was obtained from Sigma Aldrich.

\subsection{Fabrication of nanofibrous scaffolds.}

PCL was dissolved in TFE to obtain 8-10\% (w/w) solution by stirring for 1 hour. To have CS solution, it was dissolved in TFA at a concentration of $2-2.5 \%(\mathrm{w} / \mathrm{w})$ under stirring for an hour. PCL and CS were mixed with different ratios 60:40, 70:30, and 80:20 (PC: CS). After stirring for $1 \mathrm{~h}$, the solution was placed into a $5 \mathrm{ml}$ plastic syringe and fed through an 18 $\mathrm{G}$ blunted stainless steel needle at a rate of $0.7 \mathrm{ml} / \mathrm{h}$. The distance between the tip of the needle and the collector covered with an aluminum foil was set at $10-14 \mathrm{~cm}$ while a high voltage of $20 \mathrm{kV}$ was applied. The collector was rotated with a speed of $400 \mathrm{rpm}$ for random fibers and 3000 for aligned.

\subsection{Surface modifications of nanofibers.}

For PD coating, nanofibrous substrates (random and aligned mats) were immersed into a dopamine solution $(2 \mathrm{mg} / \mathrm{mL}$ in $10 \mathrm{mM}$ Tris, $\mathrm{pH} 8.5$ ) with shaking for $1 \mathrm{~h}$ at room temperature. 
The substrates were then rinsed with distilled water several times to remove the unattached dopamine molecules. The PD-coated substrates were coated with nerve growth factor (NGF) by immersing them into an NGF solution $(1 \mu \mathrm{g} / \mathrm{ml}$ in $10 \mathrm{mM}$ Tris buffer, $\mathrm{pH} 8.5)$ for $18 \mathrm{~h}$. The NGF immobilized substrates (PCL/CS-PD-NGF) were then washed with distilled water to remove the loosely bound nerve growth factors.

\subsection{Characterization of morphology, chemistry, and contact angle of nanofibers.}

Scanning electron microscopy (SEM) was used to characterize nanoscale surface morphology with and without cells. Raman spectra were recorded in the region $700-2000 \mathrm{~cm}^{-}$ ${ }^{1}$ using Raman spectroscopy (Model: Takram P50C0R10, Teksan, Iran). The wettability test was done through water contact angle measurement. For this 5 samples of each group were prepared, and contact angle measurement was done.

\subsection{Cell culture.}

PC12 cells were cultured in RPMI supplemented with 10\% FBS and 1\% penicillin/streptomycin in a $25 \mathrm{~cm}^{2}$ flask $\left(37 \mathrm{C}, 95 \%\right.$ humidity, $\left.5 \% \mathrm{CO}_{2}\right)$. After the cell number increased, the cells were detached using trypsin/EDTA and seeded on the fibers in 96 well plates. Before cell experiments, scaffolds were sterilized by UV light exposure for an hour.

The Alamar blue assay was employed to evaluate cytotoxicity and cell viability on samples (PCL, PCL/CS, PCL/CS-PD, and PCL/CS-PD-NGF). The test measured the fluorescence intensity (530 $\mathrm{nm}$ excitation, $590 \mathrm{~nm}$ emission) and was repeated on days 1, 3, and 5 using a plate reader. The morphology study of PC12 cells on samples was performed with SEM after 2 days of in vitro culture. To do this, cell-scaffold constructs were fixed with glutaraldehyde $2.5 \%$ and followed by different ethanol concentrations (50\%, 70\%, 90\%, and 100\%) to dehydrate the samples.

\section{Results and Discussion}

\subsection{Preparation and characterization of nanofibrous scaffolds.}

Production of composite scaffolds containing heterogeneous fibers of natural and synthetic polymers could provide a scaffold with desirable characteristics [24-26]. Since electrospinning is a complex process and depends on different factors, the polymers concentration ratio was studied to determine the best ratio. Figure 1(a) shows the morphology of nanofibers fabricated using different concentrations of polymers. As shown, increasing the PCL concentration from $8 \mathrm{wt} \%$ to $10 \mathrm{wt} \%$ increased the mean diameter of the fibers from 224 $\mathrm{nm}$ to $252 \mathrm{~nm}$, while CS was kept at $2 \mathrm{wt} \%$ in both formulations. As shown in Figure 1(b), by increasing polymer concentration, the fiber's diameter increased with more straight fibers crossed together with sharper angles. Other researchers reported that decreasing polymer concentration in solution followed by viscosity reduction caused beaded and thinner fibers $[23,27]$. 


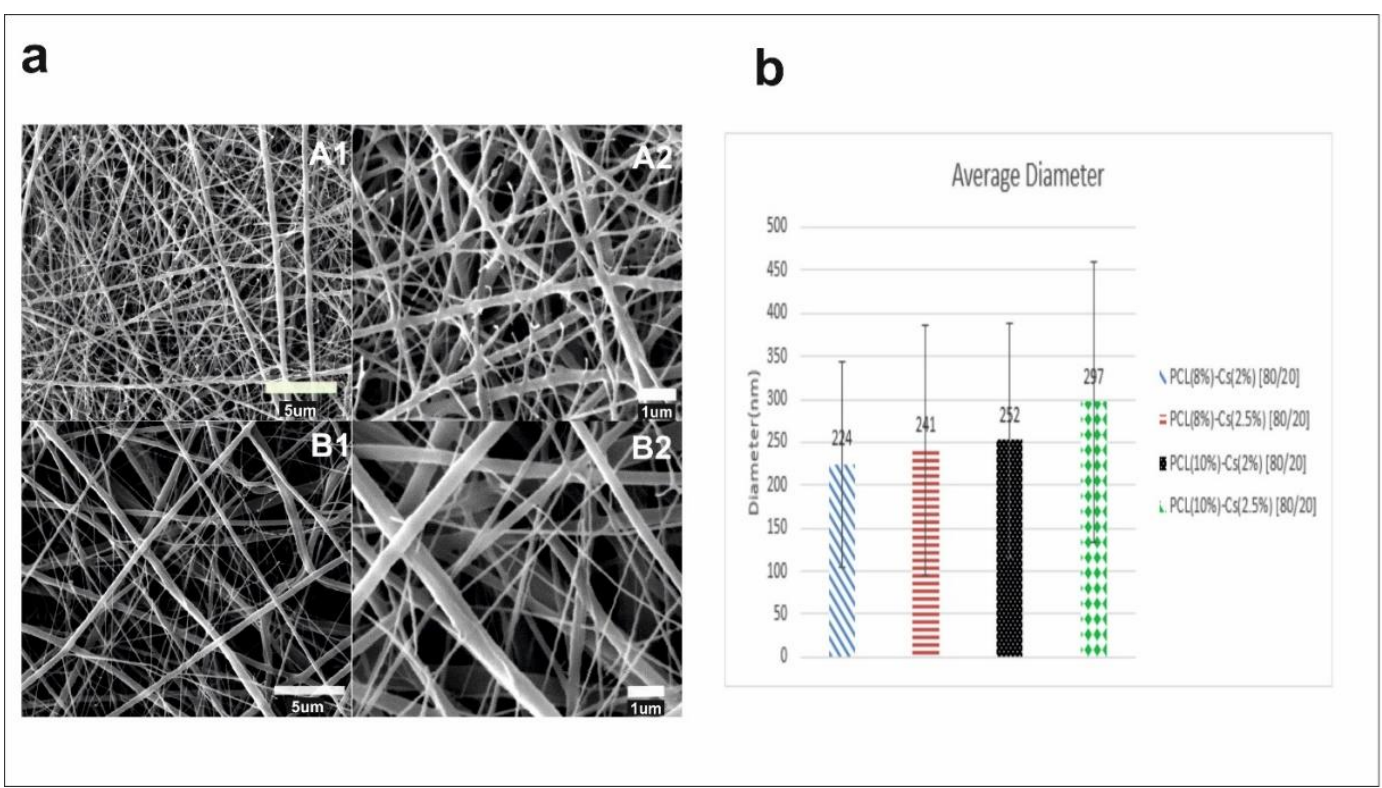

Figure 1. SEM images of PCL/CS nanofibers and their diameter analysis. (a) A1 and A2, PCL (8\%)/CS (2\%), B1 and B2, PCL (10\%)/CS (2\%); (b) Diameter analysis of PCL/CS nanofibers with different formulations. By increasing polymer concentration, the diameter of the fiber increased.

Aligned nanofibers play a critical role in neurite outgrowth of the neural cells when compared to random nanofibers. Neurite outgrowth and cell migration of the neural cells tend to be extended parallel with nanofibers' alignment [12]. Figure 2(a) shows SEM images of aligned and random oriented nanofibers collected on high speed rotating and static drum, respectively. Orientation distribution analysis of aligned and random nanofibers is shown, too. As it is displayed, electrospinning at about $3000 \mathrm{rpm}$ collector rotation speeds could produce aligned nanofibers [28], reducing the drum's rate to $400 \mathrm{rpm}$ [29], changed their alignment. Change in nanofibers alignment can result from the centrifugal force caused by an increase in drum rotation speed [30-32]. Besides, the diameter of the electrospun nanofibers decreased as the drum speed increased to $3000 \mathrm{rpm}$. Comparison between the diameter of aligned and random nanofibers are shown in Figure 2(b).

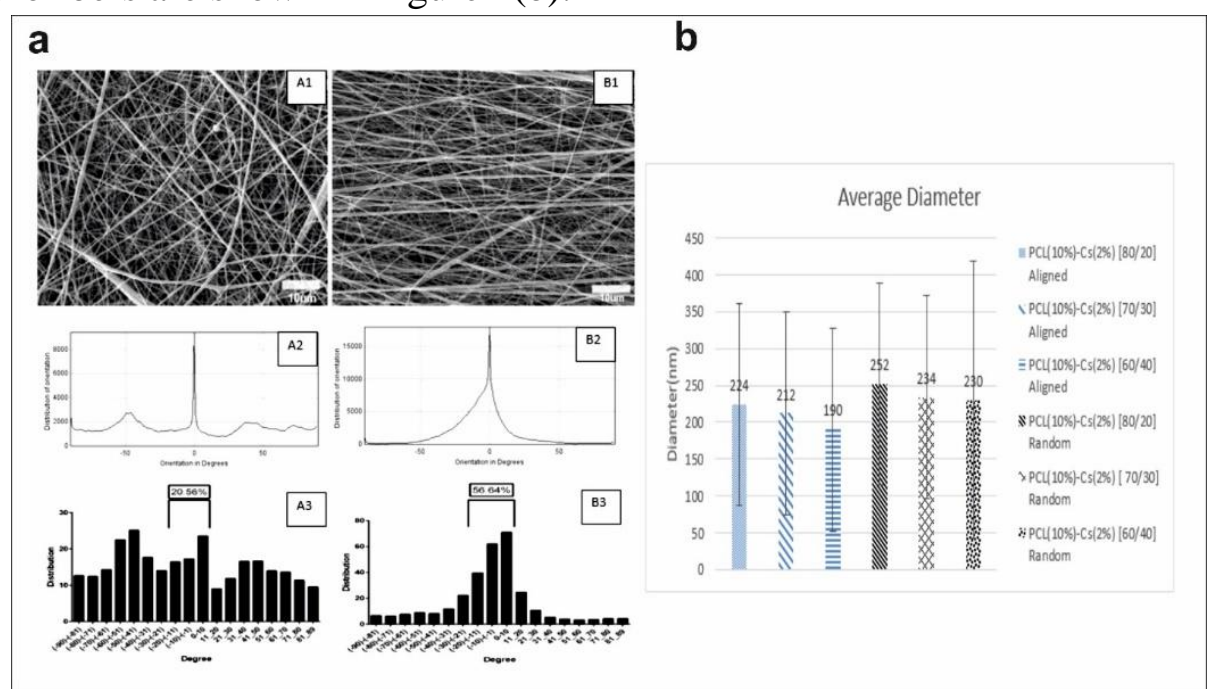

Figure 2. SEM picture and orientation distribution of random (speed of drum=400rpm) and aligned (speed of drum $=3000 \mathrm{rpm}$ ) nanofibers. (a) A1, A2, and A3 related to SEM picture and orientation distribution of random fibers while B1, B2, and B3 related to aligned one; (b) The average diameter of aligned and random nanofibers with different ratio of PCL and Cs. As it can be noticed, the fibers became more aligned and thinner by increasing drum speed. 
SEM images in Figure 3(a) display dopamine-modified nanofibers. The average diameter of nanofibers did not increase significantly $(\mathrm{p}<0.05)$ after dopamine coating (Figure 3(b)), so the polydopamine layer was very thin. It is in agreement with previous studies [33]. Moreover, this thin layer could not decrease the porosity percentage significantly, with slight changes from $48.5 \%$ to $47 \%(\mathrm{p}<0.05)$.

a

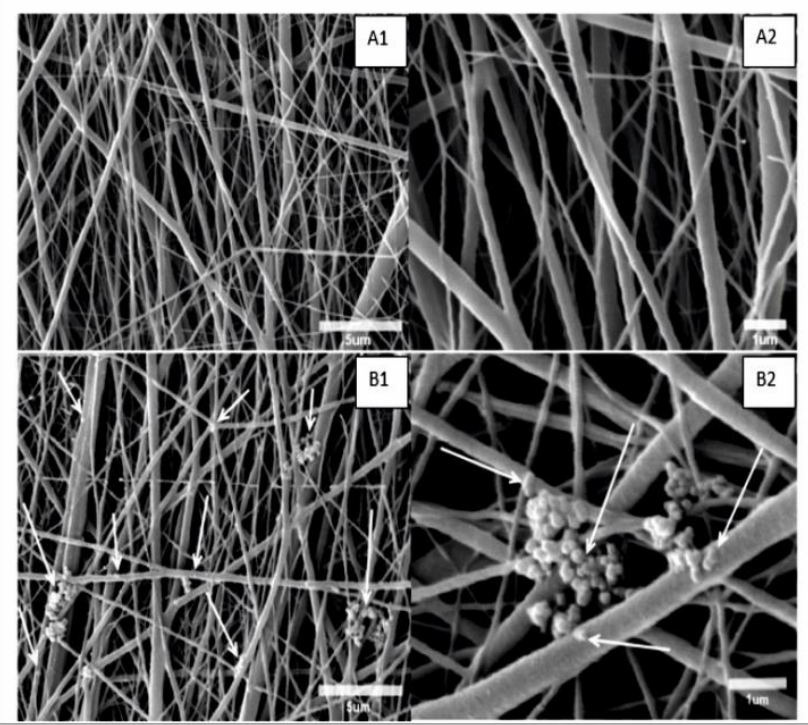

b

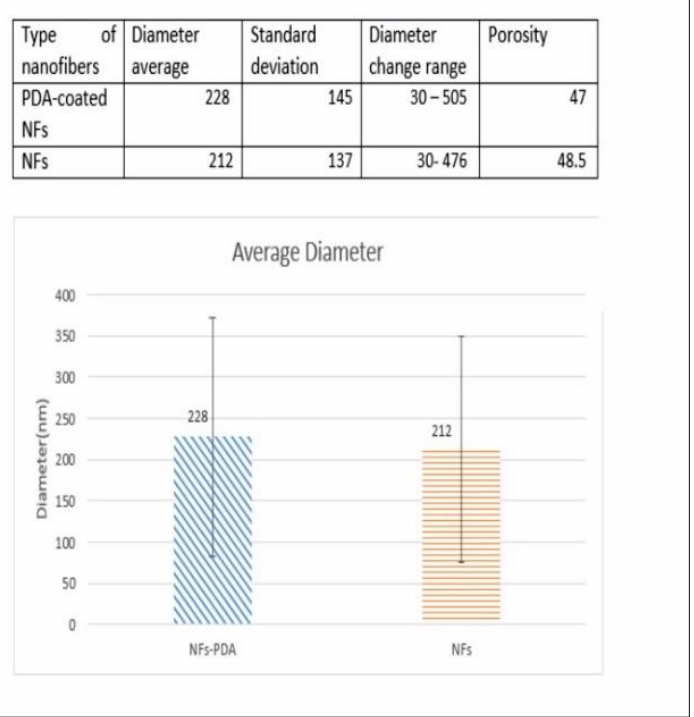

Figure 3. Poly dopamine modified PCL/CS nanofibers. (a) SEM images of nanofibers before (A) and after (B) dopamine coating; (b) Comparison between the diameter of nanofibers before and after dopamine coating.

There was no significant difference in fiber diameter before and after dopamine coating $(\mathrm{p}<0.05)$.

A wettability test was done to confirm the presence of the PD layer further. Figure 4 shows the contact angle measurements, which provide information on changes in surface properties as a result of surface modification. The static contact angle of water droplets on PCL nanofibers was $133 \pm 21^{\circ}$, which was significantly $(\mathrm{p}<0.05)$ different from PCL/CS nanofiber $\left(12.9 \pm 2^{\circ}\right)$. It can be attributed to the presence of amine groups of chitosan. Junka et al. reported that by increasing the CS ratio in PCL/CS nanofibers, the hydrophobicity decreased $[34,35]$. On the other hand, the contact angle of polydopamine coated nanofibers $\left(66 \pm 3^{\circ}\right)$ was greater than PCL/CS nanofibers. As Nielsen reported, two factors can change wettability: morphology and changes in surface chemistry.

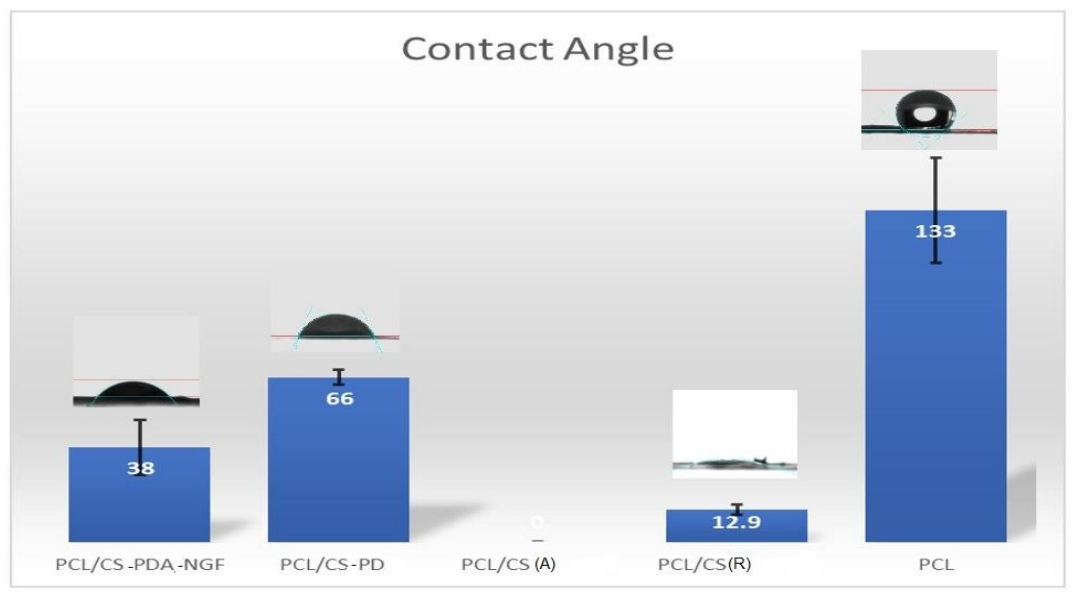

Figure 4. Contact angle of different nanofibrous scaffolds. The addition of NGF enhanced the hydrophilicity of PD coated PCL/CS nanofibers. 
The reduction of hydrophilicity of polydopamine coated nanofibers can be mainly attributed to CS amine groups' involvement with dopamine's functional groups. The dopamine layer could cover the fibers and reduce the porosity of scaffolds. Hence scaffolds could not trap the water molecules as much as before, and hydrophilicity was reduced [36-38]. The addition of NGF on the nanofibers enhanced the hydrophilicity by changing surface chemistry [39]. The hydrophilicity of aligned fibers was more than random ones, confirming that topography and morphology can influence contact angle as well as chemical properties [40,41].

Raman spectroscopy confirmed dopamine's ability to polymerize on the surface of PCL/CS nanofibers to form the PD layer [42,43]. As shown in Figure 5, strong bands between 1400 and $1500 \mathrm{~cm}^{-1}$ are related to $\delta(\mathrm{CH} 2)$ vibrations [44,45]. Whereas PD-coated nanofibers displayed an additional peak at about $1600 \mathrm{~cm}^{-1}$, which belongs to catechol's deformation, indicating the successful deposition of the PD layer onto nanofibers [46,47]. This peak could be observed due to the presence of CS, but its sharpness and intensity ensure dopamine existence [42].

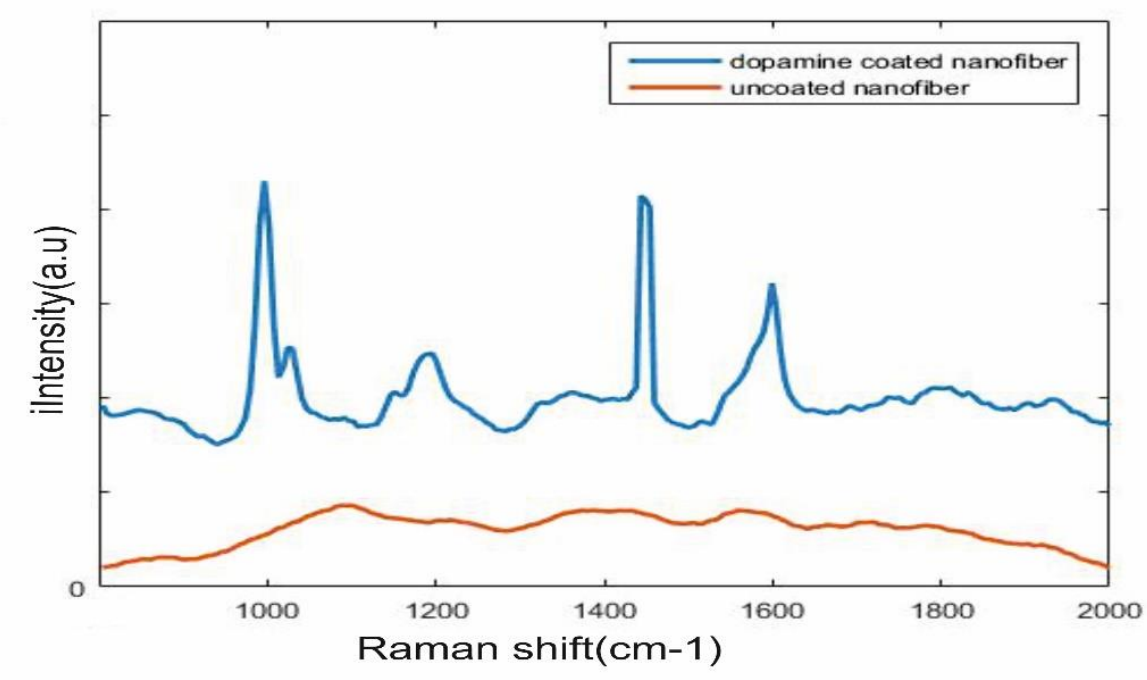

Figure 5. Raman spectra of electrospun PD coated PCL/CS nanofibers. The peak at about $1600 \mathrm{~cm}^{-1}$ corresponds to the deformation of catechol.

Suitable mechanical properties are required for scaffolds to withstand applied stresses during the surgical procedure with adequate implantation flexibility [24,48]. To compare nanofibers' tensile properties with and without surface modification, mechanical properties such as ultimate tensile stress and Young's modulus were evaluated. The ultimate tensile stress represents the sample's first failure points, and Young's modulus has been defined as the slope of the linear region of the stress-strain curve below the yield stress [34]. Results are gathered in table1. The Young's modulus of PCL, PCL- CS (random), PCL-CS (aligned), and PCL/CSPD nanofiber was 15.68, 22.87, 10.48, and 9.56 MPa, respectively. Previous studies reported that a thick coating of PD can affect the nanofibrous scaffold's mechanical behavior, leading to less elastic and more rigid materials [49-51].

Table 1. Mechanical properties of different scaffolds.

\begin{tabular}{l|l|l} 
Nanofiber & Young's modulus (MPa) & Ultimate tensile stress (MPa) \\
\hline PCL & 15.68 & 0.79 \\
\hline PCL-Cs(Random) & 22.87 & 1.16 \\
\hline PCL-Cs(Aligned) & 10.48 & 1.55 \\
\hline PCL-Cs-PDA & 9.56 & 1.05
\end{tabular}


Nonetheless, our results showed that the PD layer formed during one-hour incubation was not thick enough to significantly change mechanical properties.

\subsection{Cell-scaffold interaction.}

Cell attachment to the scaffold is a critical step in nerve regeneration. Hence the scaffold should mimic the natural extracellular matrix (ECM) properties such as composition, topography, mechanical properties, and biological cues [34].

To evaluate the performance of scaffolds in vitro, PCL/CS-PD-NGF, PCL/CS-PD, PCL-CS, and PCL scaffolds were tested to study PC12 cell attachment and proliferation at 3time points. Alamar blue assay showed that the number of PC12 cells on PCL/CS-PD-NGF scaffold increased significantly higher than other scaffolds and control groups after 24 hours $(\mathrm{p}<0.05)$ (Figure 6). After 72 hours, although the number of cells decreased on the PCL/CSPD-NGF scaffolds, cell viability on this scaffold remained significantly higher than other groups $(\mathrm{p}<0.05)$. As NGF on the scaffold induces neurite extension in PC12 cells, they need more space to stretch out. Strongly attached PC12 cells extended their neuritis while the ones with no strong adhesion might be detached from the scaffolds during the time. This event might lead to a decreased number of differentiated PC12 cells on the scaffolds with less desirable interactions with the scaffolds. Lee et al. immobilized NGF covalently on PLGA-Ppy and reported that immobilized NGF on the nanofibers was as effective as exogenous NGF to induce neurites formation and extension [19].
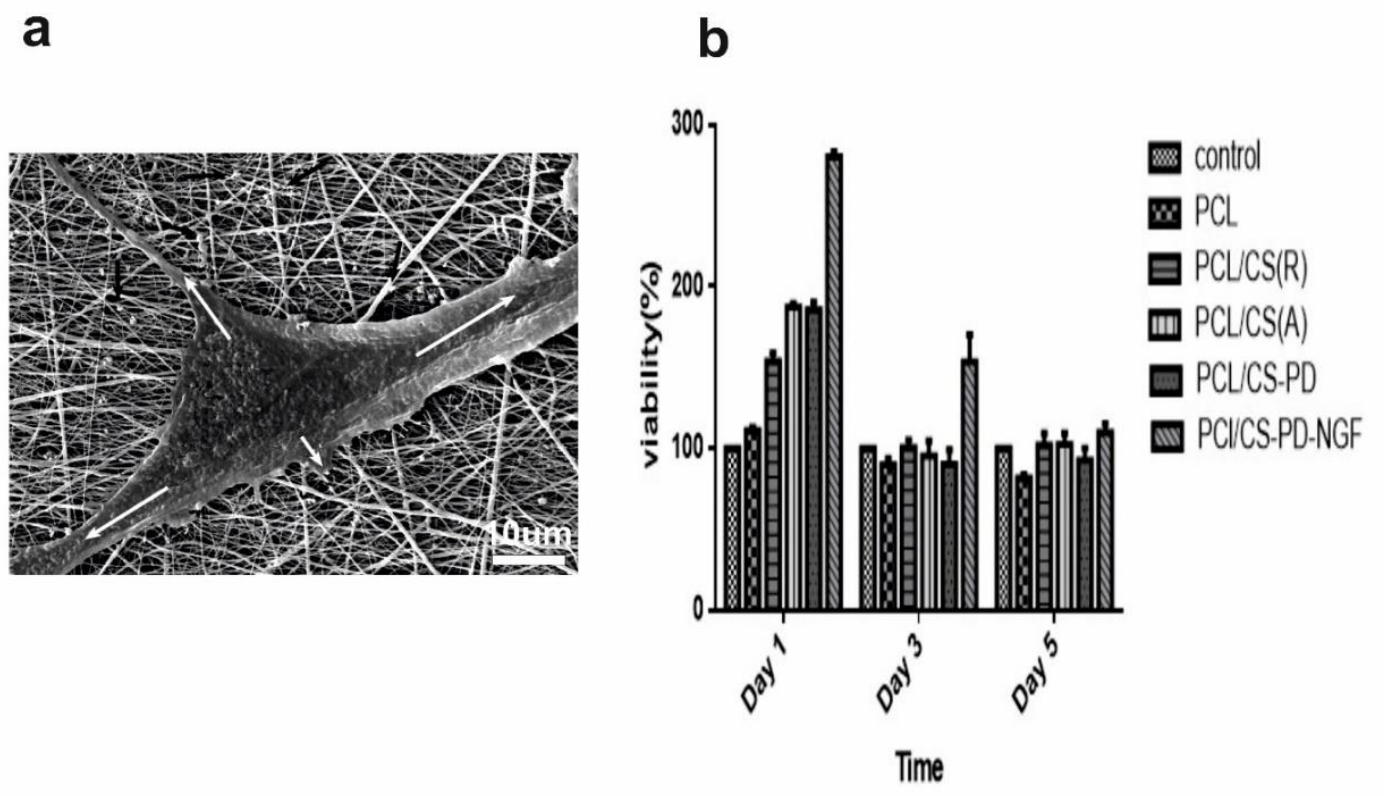

Figure 6. Alamar blue assay of PC12 cells on nanofibrous scaffolds. (a) NGF on the scaffold induces differentiation and neurite extension in PC12 cells. White arrows show the direction of extensions; (b) Proliferation on day 5 was similar among all different groups without significant statistical difference, however, the number of PC12 cells on NGF immobilized scaffold was significantly higher than PCL scaffold on day 5.

To verify Alamar blue assays' results, the fluorescence microscope images of PC12 cells grown on different scaffolds were provided after 24 hours (Figure 7). As can be seen, the cell attachment on PCL/CS-PD-NGF scaffolds was significantly higher than other groups $(\mathrm{p}<0.05)$, indicating desirable interactions between the cells and scaffolds. As it can be figured 
out, the growth of PC12 cells on PCL-Cs nanofibers was higher than PCL nanofibers because of the hydrophilicity of PCL-Cs and the presence of amine groups in PCL-Cs nanofibers.

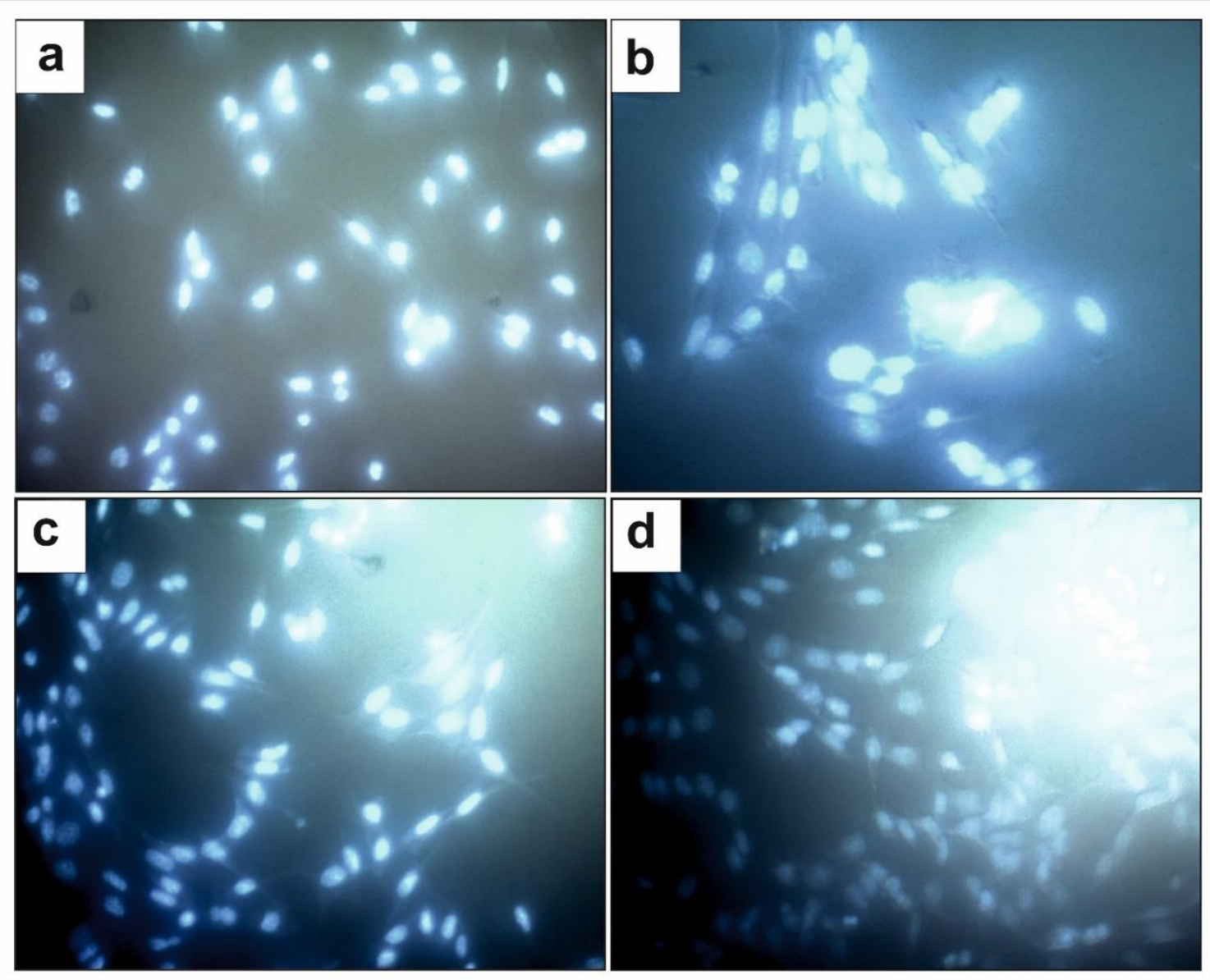

Figure 7. The fluorescence microscopy of PC12 cells on (a) PCL nanofibers; (b) PCL-Cs nanofibers; (c) PCL/Cs-PD nanofibers; (d) PCL/Cs-PDA-NGF nanofibers. PC12 cells attached to all scaffolds but proliferation and attachment to NGF immobilized scaffolds were more than other scaffolds. Cell attachment on PCL/CS-PDNGF scaffold was higher than other groups.

SEM images of PC12 cells on random and aligned nanofibrous scaffolds displayed the effects of topographic and biological cues on cell morphology. As shown in Figure 8, PC12 cells on aligned nanofibrous scaffolds oriented aligned and more spread out the cells' extensions than the random nanofibrous scaffold, which induced an irregular cellular orientation.

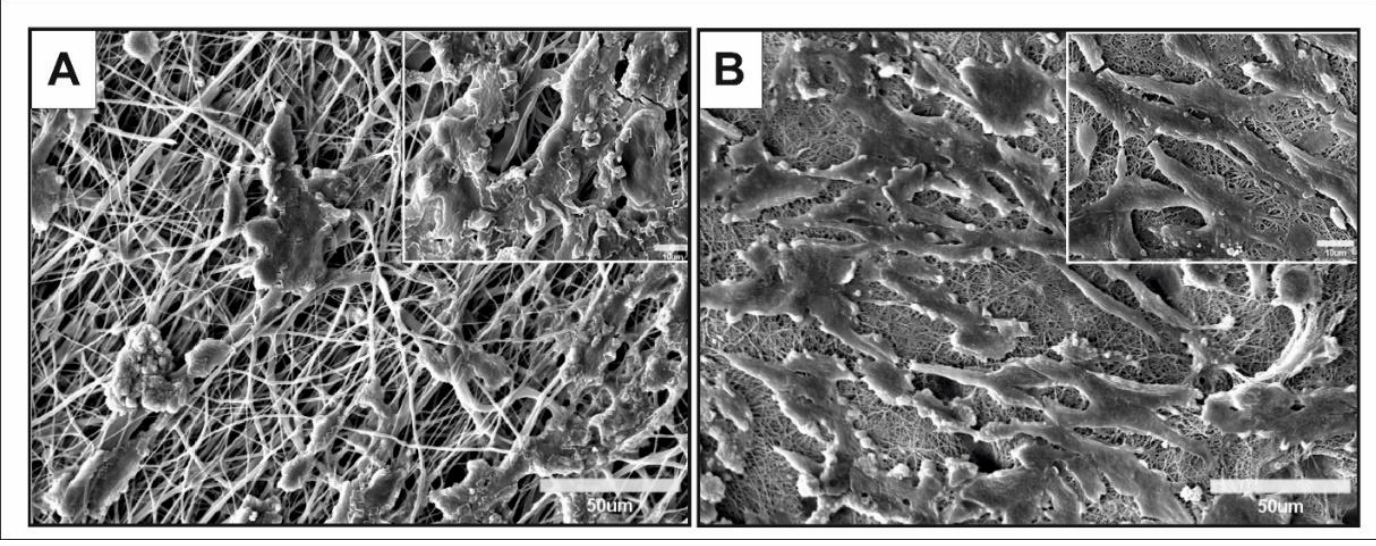

Figure 8. SEM pictures of PC12 on Random and aligned PCL-Cs nanofibers. (A) Random scaffold induced an irregular cellular orientation; (B) PC12 cells on the aligned nanofibrous scaffold were aligned and spreader. 
The SEM images of PC12 cells on aligned PCL/CS-PD, PCL/CS-PD-NGF, and PCL/CS are shown in Figure 9. The cells cultured on aligned scaffolds showed bipolar morphology, which was allied with the direction of nanofibers. The cells displayed a more elongated morphology on NGF immobilized nanofibers. The immobilized NGF increased neuronal viability and induced differentiation with enhanced neurite outgrowth. It could be attributed to the interaction of NGF with receptors such as TrkA and p75 [18,52]. Based on this mechanism, NGF does not need to be internalized by the cell and could induce long-term effect without inhibitory receptor down-regulation [53-55].
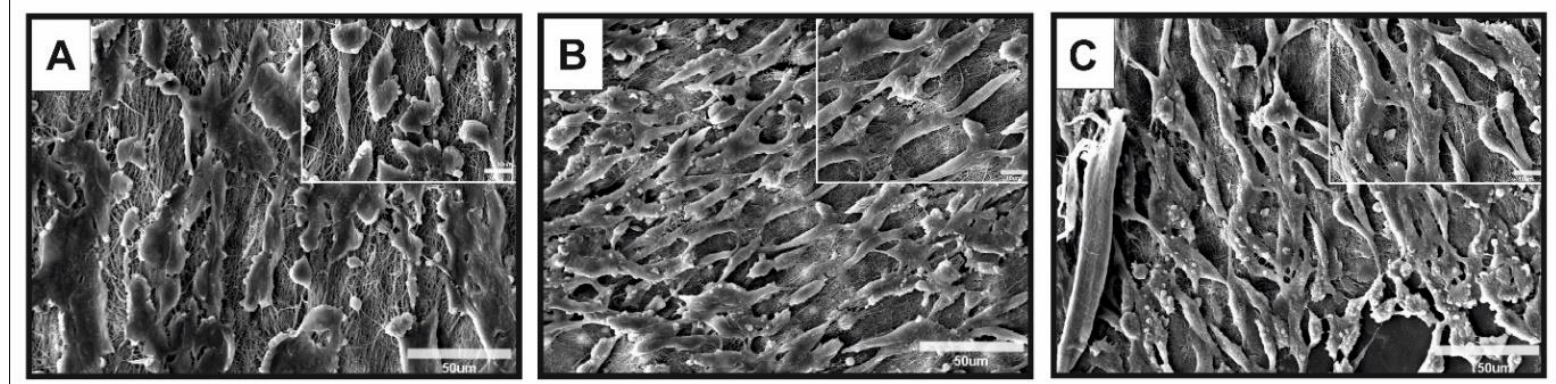

Figure 9. SEM images of PC12 cells on (A) PCL-Cs (Aligned) nanofibers; (B) PCL-Cs-PDA nanofibers; (C) PCL-Cs-PDA-NGF nanofibers. Cells were spreader and longer on NGF immobilized nanofibers.

\section{Conclusions}

The results of this study revealed that aligned PCL/CS nanofibers could provide essential requirements for neural cell growth, owing to their appropriate physicochemical and topographical features. Further improvement was achieved by functionalization of the scaffolds with NGF, as an effective agent for nerve regeneration. PCL/CS-PD-NGF nanofibrous scaffolds supported PC12 cell growth and differentiation with appropriate topographical and biological cues. Results showed that aligned nanofibers with immobilized NGF can increase cell attachment and proliferation in a particular direction with the aim of nerve regeneration.

\section{Funding}

This research was funded by Tehran University of Medical Sciences, grant number 93-03-8727087.

\section{Acknowledgments}

The authors declared no acknowledgments.

\section{Conflicts of Interest}

The authors declare no conflict of interest.

\section{References}

1. Steed, M.B.; Mukhatyar, V.; Valmikinathan, C.; Bellamkonda, R.V. Advances in bioengineered conduits for peripheral nerve regeneration. Atlas of the Oral and Maxillofacial Surgery Clinics 2011, 19, 119-130, https://doi.org/10.1016/j.cxom.2010.11.007.

2. Nazeri, N.; Tajerian, R.; Arabpour, Z.; Hadjighassem, M.R.; Gheibi, N.; Manouchehrabadi, M.; Ghanbari, H. Bioinspired immobilization of carbon nanotubes on scaffolds for nerve regeneration. Bioinspired, Biomimetic and Nanobiomaterials 2019, 8, 198-205, https://doi.org/10.1680/jbibn.18.00033. 
3. Gu, X.; Ding, F.; Yang, Y.; Liu, J. Construction of tissue engineered nerve grafts and their application in peripheral nerve regeneration. Prog. Neurobiol. 2011, 93, 204-230, https://doi.org/10.1016/j.pneurobio.2010.11.002.

4. Davoudi, P.; Assadpour, S.; Derakhshan, M.A.; Ai, J.; Solouk, A.; Ghanbari, H. Biomimetic modification of polyurethane-based nanofibrous vascular grafts: A promising approach towards stable endothelial lining. Mater. Sci. Eng. C Mater. Biol. Appl. 2017, 80, 213-221, https://doi.org/10.1016/j.msec.2017.05.140.

5. Tunali-Akbay, T.; Kahraman, M.V.; Oktay, B.; İpekci, H.; Kayaman-Apohan, N. Bioactivated poly (vinyl alcohol) /poly(acrylic acid) based nanofiber for high-performance membrane techniques. Letters in Applied NanoBioScience 2020, https://doi.org/10.33263/LIANBS91.819823.

6. Li, W.; Guo, Y.; Wang, H.; Shi, D.; Liang, C.; Ye, Z.; Qing, F.; Gong, J. Electrospun nanofibers immobilized with collagen for neural stem cells culture. J. Mater. Sci. Mater. Med. 2008, 19, 847-854, https://doi.org/10.1007/s10856-007-3087-5.

7. Nazeri, N.; Karimi, R.; Ghanbari, H. The effect of surface modification of poly-lactide-co-glycolide/carbon nanotube nanofibrous scaffolds by laminin protein on nerve tissue engineering. Journal of Biomedical Materials Research Part A 2020, https://doi.org/10.1002/jbm.a.37013.

8. Kijeńska, E.; Prabhakaran, M.P.; Swieszkowski, W.; Kurzydlowski, K.J.; Ramakrishna, S. Interaction of Schwann cells with laminin encapsulated PLCL core-shell nanofibers for nerve tissue engineering. Eur. Polym. J. 2014, 50, 30-38, https://doi.org/10.1016/j.eurpolymj.2013.10.021.

9. Nazeri, N.; Avadi, M.R.; Faramarzi, M.A.; Safarian, S.; Tavoosidana, G.; Khoshayand, M.R.; Amani, A. Effect of preparation parameters on ultra low molecular weight chitosan/hyaluronic acid nanoparticles. Int. J. Biol. Macromol. 2013, 62, 642-646, https://doi.org/10.1016/j.ijbiomac.2013.09.041.

10. Amanzadi, B.; Mirzaei, E.; Hassanzadeh, G.; Mahdaviani, P.; Boroumand, S.; Abdollahi, M.; Hosseinabdolghaffari, A.; Majidi, R.F. Chitosan-based layered nanofibers loaded with herbal extract as wound-dressing materials on wound model studies. Biointerface Res. Appl. Chem 2019, 9, 3979-3986, https://doi.org/10.33263/briac94.979986.

11. Tajdini, K.; Shakeri, A.; Naijian, F. Nanocomposite hydrogel of chitosan-g-poly acrylamide/ nanoclay: effect of degree of crosslinking on their swelling. Letters in Applied NanoBioScience 2020, https://doi.org/10.33263/LIANBS92.995999.

12. Cooper, A.; Bhattarai, N.; Zhang, M. Fabrication and cellular compatibility of aligned chitosan-PCL fibers for nerve tissue regeneration. Carbohydr. Polym. 2011, 85, 149-156, https://doi.org/10.1016/j.carbpol.2011.02.008.

13. Xie, J.; MacEwan, M.R.; Willerth, S.M.; Li, X.; Moran, D.W.; Sakiyama-Elbert, S.E.; Xia, Y. Conductive core-sheath nanofibers and their potential application in neural tissue engineering. Adv. Funct. Mater. 2009, 19, 2312-2318, https://doi.org/10.1002/adfm.200801904.

14. Lien, B.V.; Brown, N.J.; Ransom, S.C.; Lehrich, B.M.; Shahrestani, S.; Tafreshi, A.R.; Ransom, R.C.; Sahyouni, R. Enhancing peripheral nerve regeneration with neurotrophic factors and bioengineered scaffolds: A basic science and clinical perspective. J. Peripher. Nerv. Syst. 2020, 25, 320-334, https://doi.org/10.1111/jns.12414.

15. Gomez, N.; Schmidt, C.E. Nerve growth factor-immobilized polypyrrole: Bioactive electrically conducting polymer for enhanced neurite extension. Journal of Biomedical Materials Research Part A 2007, 81, 135149, https://doi.org/10.1002/jbm.a.31047.

16. Gomez, N.; Lu, Y.; Chen, S.; Schmidt, C.E. Immobilized nerve growth factor and microtopography have distinct effects on polarization versus axon elongation in hippocampal cells in culture. Biomaterials 2007, 28, 271-284, https://doi.org/10.1016/j.biomaterials.2006.07.043.

17. Kijeńska-Gawrońska, E.; Bolek, T.; Bil, M.; Swieszkowski, W. Alignment and bioactive molecule enrichment of bio-composite scaffolds towards peripheral nerve tissue engineering. Journal of Materials Chemistry B 2019, 7, 4509-4519, https://doi.org/10.1039/C9TB00367C.

18. Pan, S.; Zhao, Y.; Qiao, X.; Qi, Z.; Fu, C.; Kong, W.; Liu, Q.; Yang, X. PLGA porous scaffolds by polydopamine-assisted immobilization of NGF for spinal cord injury repair. Materials Research Express 2019, 6, 045024, https://doi.org/10.1088/2053-1591/aafa8a.

19. Lee, J.Y.; Bashur, C.A.; Milroy, C.A.; Forciniti, L.; Goldstein, A.S.; Schmidt, C.E. Nerve growth factorimmobilized electrically conducting fibrous scaffolds for potential use in neural engineering applications. IEEE Trans. NanoBiosci. 2012, 11, 15-21, https://doi.org/10.1109/TNB.2011.2159621.

20. Lee, H.; Rho, J.; Messersmith, P.B. Facile conjugation of biomolecules onto surfaces via mussel adhesive protein inspired coatings. Adv. Mater. 2009, 21, 431-434, https://doi.org/10.1002/adma.200801222. 
21. Yang, K.; Lee, J.S.; Kim, J.; Lee, Y.B.; Shin, H.; Um, S.H.; Kim, J.B.; Park, K.I.; Lee, H.; Cho, S.-W. Polydopamine-mediated surface modification of scaffold materials for human neural stem cell engineering. Biomaterials 2012, 33, 6952-6964, https://doi.org/10.1016/j.biomaterials.2012.06.067.

22. Cui, Z.; Lin, J.; Zhan, C.; Wu, J.; Shen, S.; Si, J.; Wang, Q. Biomimetic composite scaffolds based on surface modification of polydopamine on ultrasonication induced cellulose nanofibrils (CNF) adsorbing onto electrospun thermoplastic polyurethane (TPU) nanofibers. J. Biomater. Sci. Polym. Ed. 2020, 31, 561-577, https://doi.org/10.1080/09205063.2019.1705534.

23. Houshyar, S.; Pillai, M.M.; Saha, T.; Sathish-Kumar, G.; Dekiwadia, C.; Sarker, S.R.; Sivasubramanian, R.; Shanks, R.A.; Bhattacharyya, A. Three-dimensional directional nerve guide conduits fabricated by dopaminefunctionalized conductive carbon nanofibre-based nanocomposite ink printing. RSC Advances 2020, 10, 40351-40364, https://doi.org/10.1039/D0RA06556K.

24. Ghasemi-Mobarakeh, L.; Prabhakaran, M.P.; Morshed, M.; Nasr-Esfahani, M.-H.; Ramakrishna, S. Electrospun poly ( $\varepsilon$-caprolactone)/gelatin nanofibrous scaffolds for nerve tissue engineering. Biomaterials 2008, 29, 4532-4539, https://doi.org/10.1016/j.biomaterials.2008.08.007.

25. Talebi, A.; Labbaf, S.; Karimzadeh, F. Polycaprolactone-chitosan-polypyrrole conductive biocomposite nanofibrous scaffold for biomedical applications. Polym. Compos. 2020, 41, 645-652, https://doi.org/10.1002/pc.25395.

26. Chen, H.-W.; Lin, M.-F. Characterization, Biocompatibility, and Optimization of Electrospun SF/PCL/CS Composite Nanofibers. Polymers 2020, 12, 1439, https://doi.org/10.3390/polym12071439.

27. Park, S.; Kim, J.; Lee, M.-K.; Park, C.; Jung, H.-D.; Kim, H.-E.; Jang, T.-S. Fabrication of strong, bioactive vascular grafts with PCL/collagen and PCL/silica bilayers for small-diameter vascular applications. Materials \& Design 2019, 181, 108079, https://doi.org/10.1016/j.matdes.2019.108079.

28. Thomas, V.; Jose, M.V.; Chowdhury, S.; Sullivan, J.F.; Dean, D.R.; Vohra, Y.K. Mechano-morphological studies of aligned nanofibrous scaffolds of polycaprolactone fabricated by electrospinning. J. Biomater. Sci. Polym. Ed. 2006, 17, 969-984, https://doi.org/10.1163/156856206778366022.

29. Paskiabi, F.A.; Mirzaei, E.; Amani, A.; Shokrgozar, M.A.; Saber, R.; Faridi-Majidi, R. Optimizing parameters on alignment of PCL/PGA nanofibrous scaffold: an artificial neural networks approach. Int. J. Biol. Macromol. 2015, 81, 1089-1097, https://doi.org/10.1016/j.ijbiomac.2014.10.040.

30. Zhang, Z.-M.; Duan, Y.-S.; Xu, Q.; Zhang, B. A review on nanofiber fabrication with the effect of high-speed centrifugal force field. Journal of Engineered Fibers and Fabrics 2019, 14, 1558925019867517, https://doi.org/10.1177/1558925019867517.

31. Dos Santos, D.M.; Correa, D.S.; Medeiros, E.S.; Oliveira, J.E.; Mattoso, L.H. Advances in Functional Polymer Nanofibers: From Spinning Fabrication Techniques to Recent Biomedical Applications. ACS Applied Materials \& Interfaces 2020, 12, 45673-45701, https://doi.org/10.1021/acsami.0c12410.

32. Aijaz, M.O.; Karim, M.R.; Alharbi, H.F.; Alharthi, N.H. Novel optimised highly aligned electrospun PEIPAN nanofibre mats with excellent wettability. Polymer 2019, 180, 121665, https://doi.org/10.1016/j.polymer.2019.121665.

33. Ku, S.H.; Park, C.B. Human endothelial cell growth on mussel-inspired nanofiber scaffold for vascular tissue engineering. Biomaterials 2010, 31, 9431-9437, https://doi.org/10.1016/j.biomaterials.2010.08.071.

34. Junka, R.; Valmikinathan, C.M.; Kalyon, D.M.; Yu, X. Laminin functionalized biomimetic nanofibers for nerve tissue engineering. Journal of biomaterials and tissue engineering 2013, 3, 494-502, https://doi.org/10.1166/jbt.2013.1110.

35. Gargoubi, S.; Saghrouni, F.; Chevallier, P.; Tolouei, R.; Boudokhane, C.; Ladhari, N.; Mantovani, D. Polydopamine-modified interface improves the immobilization of natural bioactive-dye onto textile and enhances antifungal activity. Biointerphases 2020, 15, 041011, https://doi.org/10.1116/6.0000295.

36. Chakrapani, V.Y.; Gnanamani, A.; Giridev, V.; Madhusoothanan, M.; Sekaran, G. Electrospinning of type I collagen and PCL nanofibers using acetic acid. J. Appl. Polym. Sci. 2012, 125, 3221-3227, https://doi.org/10.1002/app.36504.

37. Nazeri, N.; Derakhshan, M.A; Ghanbari H. Novel electro-conductive nanocomposites based on electrospun PLGA/CNT for biomedical applications. J Mater Sci Mater Med. 2018, 29(11):168. https://doi.org/10.1007/s10856-018-6176-8.

38. Cheng, B.; Ishihara, K. Formation of stable polydopamine layer on polytetrafluoroethylene substrate by hybrid process involved plasma treatment and spontaneous chemical reactions. Materials Today Communications 2020, 22, 100774, https://doi.org/10.1016/j.mtcomm.2019.100774. 
39. Johnson, E.O.; Soucacos, P.N. Nerve repair: experimental and clinical evaluation of biodegradable artificial nerve guides. Injury 2008, 39, 30-36, https://doi.org/10.1016/j.injury.2008.05.018.

40. Ye, K.; Kuang, H.; You, Z.; Morsi, Y.; Mo, X. Electrospun nanofibers for tissue engineering with drug loading and release. Pharmaceutics 2019, 11, 182, https://doi.org/10.3390/pharmaceutics11040182.

41. Le, A.N.-M.; Tran, N.M.-P.; Phan, T.B.; Tran, P.A.; Dai Tran, L.; Nguyen, T.H. Poloxamer additive as luminal surface modification to modulate wettability and bioactivities of small-diameter polyurethane/polycaprolactone electrospun hollow tube for vascular prosthesis applications. Materials Today Communications 2020, 101771, https://doi.org/10.1016/j.mtcomm.2020.101771.

42. Sanna, V.; Roggio, A.M.; Siliani, S.; Piccinini, M.; Marceddu, S.; Mariani, A.; Sechi, M. Development of novel cationic chitosan-and anionic alginate-coated poly(D,L-lactide-co-glycolide) nanoparticles for controlled release and light protection of resveratrol. Int J Nanomedicine 2012, 7, 5501-5516, https://doi.org/10.2147/IJN.S36684.

43. Ermeydan, M.A.; Cabane, E.; Hass, P.; Koetz, J.; Burgert, I. Fully biodegradable modification of wood for improvement of dimensional stability and water absorption properties by poly( $\varepsilon$-caprolactone) grafting into the cell walls. Green Chem. 2014, 16, 3313, https://doi.org/10.1039/c4gc00194j.

44. Souza, N.L.G.D.; Salles, T.F.; Brandão, H.M.; Edwards, H.G.M.; Oliveira, L.F.C.d. Synthesis, Vibrational Spectroscopic and Thermal Properties of Oxocarbon Cross-Linked Chitosan. J. Braz. Chem. Soc. 2015, https://doi.org/10.5935/0103-5053.20150090.

45. Baranowska-Korczyc, A.; Warowicka, A.; Jasiurkowska-Delaporte, M.; Grześkowiak, B.; Jarek, M.; Maciejewska, B.M.; Jurga-Stopa, J.; Jurga, S. Antimicrobial electrospun poly( $\varepsilon$-caprolactone) scaffolds for gingival fibroblast growth. RSC Adv. 2016, 6, 19647-19656, https://doi.org/10.1039/c6ra02486f.

46. Gao, X.; Zhang, X.; Song, J.; Xu, X.; Xu, A.; Wang, M.; Xie, B.; Huang, E.; Deng, F.; Wei, S. Osteoinductive peptide-functionalized nanofibers with highly ordered structure as biomimetic scaffolds for bone tissue engineering. Int J Nanomedicine 2015, 10, 7109-7128, https://doi.org/10.2147/IJN.S94045.

47. Kianersi, S.; Varjani, A.A.A.; Solouk, A.; Ai, J.; Lee, B.P. Mussel-Inspired Polydopamine-coated Silk Fibroin as a Promising Biomaterial. Bioinspired, Biomimetic and Nanobiomaterials 2020, 1-7, https://doi.org/10.1680/jbibn.19.00045.

48. Ardhani, R.; Ana, I.D.; Tabata, Y. Gelatin hydrogel membrane containing carbonate hydroxyapatite for nerve regeneration scaffold. Journal of Biomedical Materials Research Part A 2020, https://doi.org/10.1002/jbm.a.37000.

49. Xie, J.; Michael, P.L.; Zhong, S.; Ma, B.; MacEwan, M.R.; Lim, C.T. Mussel inspired protein-mediated surface modification to electrospun fibers and their potential biomedical applications. Journal of Biomedical Materials Research Part A 2012, 100, 929-938, https://doi.org/10.1002/jbm.a.34030.

50. Bock, N.; Pham, T.L.-B.; Nguyen, T.B.; Binh, N.T.; Tran, H.A.; Tran, P.A. Polydopamine coating of uncrosslinked chitosan as an acellular scaffold for full thickness skin grafts. Carbohydr. Polym. 2020, 116524, https://doi.org/10.1016/j.carbpol.2020.116524.

51. Teixeira, B.N.; Aprile, P.; Mendonça, R.H.; Kelly, D.J.; Thiré, R.M.d.S.M. Evaluation of bone marrow stem cell response to PLA scaffolds manufactured by 3D printing and coated with polydopamine and type I collagen. Journal of Biomedical Materials Research Part B: Applied Biomaterials 2019, 107, 37-49, https://doi.org/10.1002/jbm.b.34093.

52. Yim, E.K.; Leong, K.W. Proliferation and differentiation of human embryonic germ cell derivatives in bioactive polymeric fibrous scaffold. J. Biomater. Sci. Polym. Ed. 2005, 16, 1193-1217, https://doi.org/10.1163/156856205774269485.

53. Ito, Y. Covalently immobilized biosignal molecule materials for tissue engineering. Soft Matter 2008, 4, 4656, https://doi.org/10.1039/B708359A.

54. Kim, S.M.; Ueki, M.; Ren, X.; Akimoto, J.; Sakai, Y.; Ito, Y. Micropatterned nanolayers immobilized with nerve growth factor for neurite formation of PC12 cells. International Journal of Nanomedicine 2019, 14, 7683, https://doi.org/10.2147/IJN.S217416.

55. Zhu, L.; Jia, S.; Liu, T.; Yan, L.; Huang, D.; Wang, Z.; Chen, S.; Zhang, Z.; Zeng, W.; Zhang, Y. Aligned PCL Fiber Conduits Immobilized with Nerve Growth Factor Gradients Enhance and Direct Sciatic Nerve Regeneration. Adv. Funct. Mater. 2020, 30, 2002610, https://doi.org/10.1002/adfm.202002610. 